\title{
A IMAGINAÇÃO NARRATIVA NA PERSPECTIVA DE MARTHA NUSSBAUM: EDUCAÇÃO DAS EMOÇÕES E FORMAÇÃO HUMANA
}

\author{
NARRATIVE IMAGINATION FROM THE PERSPECTIVE OF MARTHA NUSSBAUM: \\ EDUCATION OF EMOTIONS AND HUMAN FORMATION
}

\section{LA IMAGINACIÓN NARRATIVA DESDE LA PERSPECTIVA DE MARTHA NUSSBAUM: EDUCACIÓN DE LAS EMOCIONES Y FORMACIÓN HUMANA}

\author{
Altair Alberto Fávero ${ }^{1}$ \\ Camila Chiodi Agostini2 \\ Elia Maria Leandro Uangna ${ }^{3}$
}

\begin{abstract}
RESUMO
O presente texto tem por escopo analisar de que forma a educação das emoções e a imaginação narrativa podem se tornar potencialmente produtivas para constituir uma concepção alargada de formação humana. Para a filósofa americana Martha Nussbaum $(2015 ; 2014 ; 2013 ; 2012 ; 2005)$ o ensino da literatura e das artes pode estimular a compreensão de diversas formas de vivências, desenvolver o "olhar interior" dos alunos, que os ponha em contato com questões de gênero, raça, etnia e cooperação transcultural. 0 artigo procurará responder satisfatoriamente a seguinte questão: Por que a educação das emoções e a imaginação narrativa podem se tornar produtivas para construir uma concepção alargada de formação humana? Trata-se de um estudo qualitativo, exploratório e bibliográfico, ancorado no método analíticohermenêutico. Na primeira seção do texto será abordado o enfoque das capacidades e a ideia de uma noção alargada de educação; na segunda seção tratará do papel imaginação narrativa como pilar básico do cultivo da humanidade e de que forma a literatura pode contribuir para o desenvolvimento da imaginação narrativa; por fim, a última seção tratará da relação entre educação das emoções e formação humana.
\end{abstract}

\footnotetext{
1 Possui Pós-Doutorado (Bolsista Capes) pela Universidad Autónoma del Estado de México (UAEMéx), Doutorado em Educação (UFRGS), Mestre em Filosofia do Conhecimento (PUC/RS), Especialista em Epistemologia das Ciências Sociais (UPF) e Graduado em Filosofia (UPF). Atua como professor titular III e pesquisador no Curso de Filosofia, no Mestrado e Doutorado em Educação da UPF, onde coordena os projetos de Pesquisa Docência Universitária e políticas educacionais (em andamento desde março de 2012) e Políticas Curriculares para o Ensino Médio (em andamento desde outubro de 2020).

2 Doutoranda em Educação no PPGEdu/UPF (ingresso em agosto de 2020), Mestre em Ciências Humanas pela Universidade Federal da Fronteira Sul (UFFS), Campus de Erechim, orientada pelo Prof. Dr. Jerzy André Brzozowski. Título da dissertação: As Artes de Governar o Currículo da Educação Infantil: A Base Nacional Comum Curricular em discussão (2017). Especialização em Direito Público pela Fundação Meridional, IMED de Passo Fundo (2010). Graduação em Direito pela Universidade Luterana do Brasil, ULBRA, Campus Carazinho (2008). Graduada em Pedagogia pela Universidade Anhanguera, UNIDERP, Passo Fundo (2018). Servidora Pública Federal da Universidade Federal da Fronteira Sul, UFFS, Campus Passo Fundo. E-mail: camila.chiodi.agostini@gmail.com ${ }^{3}$ Mestranda em Educação no PPGEdu/UPF (ingresso em agosto de 2020), licenciada em Pedagogia pela Universidade da Integração Internacional da Lusofonia Afro-Brasileira (UNILAB) campos dos Palmares (2020), orientada pela Profa. Dra. Eliane Costa Santos com tema "Etnimatemática na produção de arroz da etnia Balanta". Bacharel em Humanidades pela mesma Universidade com orientação do Prof. Dr. Ricardino Jacinto Dumas Teixeira com tema de monografia "Participação da Etnia Balanta na Luta de Libertação e Democratização da Guiné-Bissau". (2017). E-mail: leandrouangna@gmail.com
} 
Palavras-chave: Imaginação narrativa. Formação humana. Teoria das capacidades. Educação democrática.

\begin{abstract}
The purpose of this text is to analyze how the education of emotions and the narrative imagination can become potentially productive to constitute an enlarged concept of human formation. For the American philosopher Martha Nussbaum $(2015 ; 2014 ; 2013 ; 2012 ; 2005)$ the teaching of literature and arts can stimulate the understanding of different forms of experiences, develop the students' "inner look", which puts them in touch with questions of gender, race, ethnicity and cross-cultural cooperation. The article will try to answer satisfactorily the following question: Why can the education of emotions and the narrative imagination become productive to build an enlarged conception of human formation? It is a qualitative, exploratory and bibliographic study, anchored in the analytical-hermeneutic method. In the first section of the text, the focus will be on the capacities and the idea of an enlarged notion of education ; the second section will deal with the role of narrative imagination as a basic pillar of the cultivation of humanity and how the literature can contribute to the development of narrative imagination; finally, the last section will deal with the relationship between education of emotions and human formation.
\end{abstract}

Keywords: Narrative imagination. Human formation. Theory of capacities. Democratic education.

\title{
RESUMEN
}

El propósito de este texto es analizar cómo la educación de las emociones y la imaginación narrativa pueden llegar a ser potencialmente productivas para constituir un concepto amplio de formación humana. Para la filósofa estadounidense Martha Nussbaum (2015; 2014; 2013; 2012; 2005) la enseñanza de la literatura y las artes puede estimular la comprensión de diferentes formas de experiencias, desarrollar la "mirada interior" de los estudiantes, que los pone en contacto con preguntas de género, raza, etnia y cooperación intercultural. El artículo intentará dar respuesta satisfactoria a la siguiente pregunta: ¿Por qué la educación de las emociones y la imaginación narrativa pueden volverse productivas para construir una concepción amplia de la formación humana? Se trata de un estudio cualitativo, exploratorio y bibliográfico, anclado en el método analítico-hermenéutico. En la primera sección del texto se abordará el enfoque en las capacidades y la idea de una noción amplia de educación; en el segundo apartado se abordará el papel de la imaginación narrativa como pilar básico del cultivo de la humanidad y cómo la literatura puede contribuir al desarrollo de la imaginación narrativa; finalmente, el último apartado se ocupará de la relación entre la educación de las emociones y la formación humana.

Palabras-clave: Imaginación narrativa. Formación humana. Teoría de la capacidad. Educación democrática.

\section{INTRODUÇÃO}

Em seu livro El cultivo da Humanidade, Nussbaum (2005, p.126) defende que as bases para a "imaginação cívica" devem assentar-se cedo na vida das crianças, na medida em que compartilham histórias, rimas e canções com as pessoas mais próximas. Valendo-se do Emílio de Rousseau, nossa filósofa ressalta que as crianças deveriam ser incentivadas a prestar atenção no sofrimento de outras criaturas vivas, deveriam ser estimuladas a sentir o peso e as angústias das calamidades humanas e incentivadas a inquietar-se e a perceber os perigos que constantemente rodeiam os seres humanos. Tal incentivo poderia se dar por meio de obras literárias, peças teatrais, filmes, enredos, histórias bem contadas, as quais pudessem despertar a "imaginação compassiva". Ela ressalta que "a cultura grega antiga atribuiu enorme importância a drama trágico 
porque the preocupava a educação moral do adulto jovem". Assistir a uma peça teatral não era entendido como uma "experiência estética" isolada de uma experiência de interesse cívico e político. As tragédias familiarizavam o jovem cidadão com as coisas más que podem suceder na vida humana, muito antes que a vida mesma se encarregue de fazê-lo" (NUSSBAUM, 2005, p.127).

Ao mostrar as fragilidades e debilidades humanas, as tragédias possibilitavam que os espectadores e atores, em sua imaginação, se identificassem com os distintos personagens, percebessem as igualdades e as diferenças, se colocassem no lugar do outro, percebessem 0 sofrimento, a morte, o abandono, a traição, a injustiça, a desigualdade e a invisibilidade socialmente impostas. Nesse sentido, Nussbaum (2005, p.130) ressalta que não é possível formar cidadãos democráticos sem que haja a arte literária, pois ela possibilita "desenvolver capacidades de percepção e juízo que são medulares para a democracia". Seguindo os passos de Walt Whitman, ela defende "que é essencial proporcionar ao estudo da literatura um lugar central em um currículo para a construção da cidadania, já que ela desenvolve as artes da interpretação que são essenciais para a participação e para a consciência cívica" (2005, p.131).

Algo semelhante também é defendido por John Dewey (2010, p.472-473) quando diz que "não há teste que revele com tanta segurança a parcialidade de uma filosofia quanto sua abordagem da arte e da experiência estética. A visão imaginativa é a força que unifica todos os componentes da matéria de uma obra de arte". Para ele, a arte é o lócus paradigmático dos valores, e a criação e o prazer advindo da arte são o protótipo dos objetivos dignos da condição humana. Sem a apreciação estética contemplativa, diz ele em Reconstrução em filosofia, "a humanidade poderia tornar-se uma raça de monstros econômicos [...] entediados com o lazer, ou tão somente capazes de usá-lo na exibição ostentadora e na dissipação extravagante" (DEWEY, 1958, p.127).

O presente texto tem por objetivo analisar de que forma a educação das emoções e a imaginação narrativa podem se tornar potencialmente produtivas para constituir uma concepção alargada de formação humana. Para Nussbaum (2015), o ensino da literatura e das artes pode estimular a compreensão de diversas formas de vivências, bem como pode desenvolver nos alunos um "olhar interior" que os ponha em contato com questões de gênero, raça, etnia e cooperação transcultural. O ensaio, ancorado nos escritos de Nussbaum (2015; 2014; 2013; 2012; 2005), investiga sobre a seguinte questão: por que a educação das emoções e a imaginação narrativa podem se tornar produtivas para construir uma concepção alargada de formação humana? Trata-se de um estudo qualitativo, exploratório e bibliográfico, ancorado no método analítico-hermenêutico. Na primeira seção do texto, será abordado o enfoque das capacidades e 
a ideia de uma noção alargada de educação; a segunda seção tratará do papel da imaginação narrativa como pilar básico do cultivo da humanidade e de que forma a literatura pode contribuir para o desenvolvimento da imaginação narrativa; por fim, a última seção tratará da relação entre educação das emoções e formação humana.

\section{O ENFOQUE DAS CAPACIDADES E A NOÇÃO ALARGADA DE EDUCAÇÃO}

Nunca se discutiu tanto, como na atualidade, sobre a necessidade preeminente do alcance de uma dignidade humana, de uma justiça social arraigada na concepção de efetivação e defesa do bem-estar dos indivíduos, primando-se, para isso, na concepção de uma liberdade, como a possibilidade de opção e de escolha. Essa questão intrínseca da atualidade repousa no entendimento de que tais garantias de bem-estar podem e devem ser alcançadas pela sociedade, sendo um dever do Estado e das comunidades internacionais garanti-las.

De forma muito breve, o conceito de capacidades se traduz, como um conjunto de liberdades substanciais, de oportunidades conjugadas ao indivíduo, as quais se encontram interrelacionadas para a sua efetivação e permitem o exercício da escolha e da ação. (NUSSABAUM, 2012). É esse conjunto de oportunidades garantidas de forma mínima, ou em um limite mínimo para execução, que é capaz de criar a teoria da justiça social básica, dos direitos políticos fundamentais, criando uma lista de 10 capacidades centrais. Sem adentrar em toda a teoria das capacidades apresentadas por Nussbaum (2013, p.84), consideramos ser importante destacar que, para essa concepção, um dos pontos centrais figura "[...] no que de fato as pessoas são capazes de fazer e ser, instruídas, de certa forma, pela ideia intuitiva de uma vida apropriada à dignidade do ser humano." É fato que o enfoque das capacidades "é uma explicação do mínimo de garantias sociais centrais e é compatível com diferentes visões sobre como lidar com questões de justiça e distribuição que surgiram uma vez que todos os cidadãos estivessem acima do nível mínimo." (NUSSBAUM, 2013, p.91). Nesse sentido, é possível inferir que a teoria das capacidades, sua compreensão, exercício e demanda aos órgãos públicos se tornam essenciais para o desfrute de uma vida digna, de bem-estar e com justiça social a todos, garantindo-se 0 mínimo de liberdade.

Se considerarmos que as capacidades são meios hábeis de revelar os anseios sociais em relação ao mínimo de condições de vida digna e como estes são alcançados com exercício da 
liberdade individual, talvez a concepção alargada das capacidades seja o caminho para a discussão que se conduz neste ponto do trabalho. Nosso escopo principal aqui é compreender como a educação das emoções e a imaginação narrativa são capazes de fundamentar uma formação humana voltada a uma educação integral que garanta as necessidades mínimas para ter uma vida digna, liberdade, cidadania e vida democrática.

No entanto, antes de adentrar nesse aspecto, é importante referir sobre o que se observa na atualidade, quando se discute a teoria das capacidades como forma de atendimento de um limite mínimo de vida digna, justiça social e bem-estar. Para tanto, deve-se levar em consideração que a transição para sua efetivação em políticas públicas, por meio do Estado, não é tão simples e sofre uma série de influências diretas e indiretas. Nesse ínterim, se mostra latente o exercício de forças ligadas às concepções mercadológicas, as quais simplificam as relações num âmbito comercial de perdas e ganhos, atreladas à produção e à preparação dos sujeitos para suas formas mais produtivas, economicamente falando. (BISSOTTO, 2016).

Nesse sentido, o bem-estar torna-se "um modelo predeterminado de 'estilo de vida', a ser alcançado por certa sociedade por meio de suas políticas públicas e de outras ações governamentais ou oriundas da sociedade civil" (BISSOTTO, 2016, p. 159). Com esse enfoque, define-se qual o bem-estar a ser alcançado, deixando à margem, de certa forma, a liberdade de escolha fortemente ressaltada pela teoria das capacidades. Diante desse aspecto, tal situação repercute diretamente nos modos de educação da sociedade, tendo em vista que a compreensão e o exercício das capacidades podem ser exercidos de forma direta através da educação. Por conseguinte, o que se percebe hoje é uma educação voltada claramente para preparar as novas gerações para o mercado de trabalho, sendo um objetivo escolar "abandonar tudo o que se pareça com uma 'acumulação de saberes supérfluos'", pois "o essencial repousa na capacidade do trabalhador de continuar a aprender o que the será útil profissionalmente" (LAVAL, 2004, p.49). Assim, conforme ressalta Nussbaum (2015, p. 142), "entretidos com a busca de riquezas, pedimos cada vez mais que nossas escolas produzam geradores de lucro competentes em vez de cidadãos." Perde-se, nesse caso, a oportunidade de educar para o humano, para a liberdade e assunção das capacidades que permitem o exercício do pensamento e da imaginação criativa.

Nessa visão utilitarista, a educação limita-se a ser um treinamento essencialmente profissional, em que se privilegia aquilo que pode gerar lucros em curto prazo, como as tecnologias aplicadas, o que desestimula o pensamento crítico, a cidadania e a capacidade de compreensão de outras pessoas, trazida pelas chamadas humanidades. Trata-se do investimento humano como um capital, sob lógica de empresa, segundo a qual "os novos paradigmas (...) englobam tanto 0 
mercado de trabalho como o da educação e da formação, 'formação por toda a vida' (long life training)" (LAVAL, 2004, p.370), diferentemente daquela que busca o aperfeiçoamento das capacidades.

Assim é preciso considerar, portanto, que uma perspectiva educacional voltada para a concretização do enfoque das capacidades é uma forma de educação que vê o indivíduo e 0 processo de transmissão de conhecimentos para além de uma abordagem eminentemente voltada para incremento do capital humano. Nessa concepção, a capacidade humana efetivada pela educação deve considerar o exercício de diversos papéis e não apenas propor-se a tornar 0 indivíduo mais produtivo, em nome do capital ou do lucro. 0 objetivo principal dessa educação é tornar o ser humano cada vez mais livre, esclarecido e autônomo nas suas escolhas. (CAMPOS, 2020).

Por outro lado, destacamos que, com base nos autores que balizam este estudo, tanto a imaginação quanto as emoções figuram como capacidades na teoria de Nussbaum (2012, p.54). No que concerne à imaginação, de acordo com a autora, esta é compreendida como a capacidade de se utilizar do pensamento, do raciocínio, dos sentidos e da imaginação "de forma verdadeiramente humana, sendo isso cultivado pela educação, [...] que permita a imaginação e 0 pensamento para o exercício de obras literárias, religiosas, musicais, de acordo com suas escolhas". Ou seja, além de defender a capacidade de imaginar, a autora postula o preceito de racionar como uma capacidade que resulta em uma liberdade, sendo ambos consubstanciados através da educação.

Aqui, verificamos claramente outro ponto de defesa relacionado na obra da autora, que afirma sobre a importância de uma educação voltada para o desenvolvimento do indivíduo de forma mais integral, completa, e que se torna essencial para a defesa da democracia, e por que não, para o pleno exercício das capacidades. E, para isso, o papel das artes e das humanidades é fundamental, mas deliberadamente é deixado de lado, tendo em vista a mudança de foco da atenção voltado excessivamente à competitividade e ao lucro. Nesse sentido, ela é clara ao afirmar que "nada pode ser mais determinante para a democracia do que a educação dos seus cidadãos" (NUSSBAUM, 2014, p.75). Perde-se, assim, o enfoque das áreas das humanidades, indispensáveis ao crescimento e ao bem-estar interno de qualquer democracia e as discussões fundam-se somente nas áreas ditas científicas, deixando as humanidades e as artes fora dos holofotes, como custo desnecessário.

Nussbaum é clara ao afirmar a necessária correlação entre as capacidades, as artes e as humanidades para a formação da cidadania, da democracia e do limite, além do bem-estar dos indivíduos. Outrossim, afirma que "as políticas educativas terão necessariamente de cultivar essas 
áreas mediante estratégias que deem pelo menos tanta importância aos métodos pedagógicos como ao conteúdo dos manuais obrigatórios". (NUSSBAUM. 2014, p.76). Assim, é fundamental para a educação democrática que o currículo tenha espaço para as artes e para as humanidades, para desenvolver a educação de forma participativa, de modo que a capacidade de percepção do outro por meio do seu olhar, do seu mundo, é aprimorada e estimulada. Ademais, resta clara a contribuição das artes em desenvolver a capacidade de compreender os outros para além de um corpo, reconhecendo a existência de uma alma, fortalecendo os recursos emocionais e criativos da personalidade, possibilitando que nos maravilhemos conosco mesmo e com os outros.

Cumpre esclarecer ainda que, segundo Nussbaum, ao analisar os ensinamentos de Tagore ${ }^{4}$, a fim de efetivar as capacidades, a cidadania e a democracia através do processo educacional, pode-se considerar a existência de três capacidades imprescindíveis, consubstanciadas como: a capacidade de autocrítica sobre si mesmo e sobre as suas próprias tradições, para que se permita viver uma vida de forma mais examinada ou crítica; a capacidade da pessoa de ver a si mesma como um ser humano interligado a todos os outros, por laços de reconhecimento e interesse, e, por fim, imaginação narrativa, que compreende a empatia pelos outros, de forma a se colocar no lugar do outro, reconhecendo seus sentimentos, desejos e esperanças de alguém que se encontre na situação da pessoa em questão. (NUSSBAUM, 2014). Essas capacidades, ditas primordiais, implicam uma concepção de liberdade obtida através da educação do indivíduo, para que este possa raciocinar, ter consciência do coletivo em que se está inserido, e, principalmente, estabeleça uma compressão de forma empática com o outro, colocando-se no lugar dele, estabelecendo vínculos através desse olhar sobre o outro, implicando o reconhecimento da sua humanidade. Consideramos, aqui, que a imaginação narrativa se mostra como balizadora primordial de todo esse processo, sendo esse o ponto a ser tratado a seguir.

\section{A IMAGINAÇÃO NARRATIVA COMO PILAR BÁSICO DO CULTIVO DA HUMANIDADE E 0 PAPEL DA LITERATURA}

\footnotetext{
4 Rabindranath Tagore é um renomado educador, pensador, escritor e artista da Índia, ganhador do Nobel de Literatura em 1913, e inspirador do trabalho de Nussbaum em várias de suas obras. Segundo ela, "O experimento educacional de Tagore, que teve uma grande influência na Europa, no Japão e nos Estados Unidos, tinha o foco na capacitação do aluno por meio dos métodos de discussão socrática, da exposição a diversas culturas do mundo e, acima de tudo, da introdução da música, das belas-artes, do teatro e da dança em todas as partes do currículo. Hoje em dia, ninguém liga para as idéias de Tagore na Índia, chegando mesmo a desprezá-las" (NUSSBAUM, 2015, p. 5).
} 
É comum na atualidade ter a concepção de que os fatos e a lógica são capazes de fornecer a base suficiente para que possamos nos relacionar ou interagir com o mundo ou a sociedade que nos rodeia, mas a verdade é que eles não o são - pelo menos de forma única - como se imagina. Conforme Nussbaum (2015), as pessoas interagem adequadamente com a complexidade do mundo que as rodeia por meio de conhecimento factual e de lógica, mas a imaginação narrativa faz-se necessária para que os seres humanos aprendam a lidar com suas emoções e com 0 mundo à sua volta. Nesse sentido, a pessoa adquire uma imaginação narrativa a partir do momento que tem empatia pelo outro, compreendendo como as circunstâncias o condicionam, e, ao mesmo tempo, respeitando o caráter individual e a privacidade de cada um. (NUSSBAUM, 2005).

Ainda de acordo com Nussbaum (2015), precisamos desenvolver o "olhar interior" dos alunos, e isso se faz pelas práticas das artes e pela presença das humanidades, levando em conta o cuidado com a faixa etária das crianças, bem como o desenvolvimento de cada uma. Assim, existem dois papéis importantes das artes nas escolas e faculdades: "elas desenvolvem a capacidade de brincar e de sentir empatia de modo geral e tratam de pontos cegos culturais específicos." (NUSSBAUM, 2015, p. 108). O primeiro "pode ser desempenhado por meio de atividades executadas fora do período em que o aluno se encontra na escola, embora não qualquer atividade escolhida ao acaso. $O$ segundo exige um foco mais preciso em áreas de inquietação social" (NUSSBAUM, 2015, p.108). Esses dois aspectos andam juntos, com o intuito de tornar o valor da humanidade mais visível, garantindo vidas dignas, iguais e com importância de valores para todos os seres humanos.

Assim, a partir da literatura, é possível adquirir essa capacidade, pois a leitura possibilita cultivar as emoções e a sensibilidade de se colocar no lugar dos outros e construir empatia humana. É por isso que ela tem de ser trabalhada para que tais virtudes sejam aproveitadas e não possam ser banidas do nosso juízo moral. Da mesma forma que a literatura é sustentada nas artes e estas possuem funções primordiais, como a de desafiar a sabedoria e os valores convencionais, "o ensino da literatura e das artes pode estimular a compreensão de diversas formas, por meio do envolvimento com inúmeras obras de literatura, de música, de belas-artes e de dança." (NUSSBAUM, 2015, p.106).

É importante entender que a literatura e a arte andam juntas e possuem objetivos igualmente críticos e muitas vezes não visíveis. Na interpretação de Nussbaum (2015), as crianças começam a adquirir capacidades essenciais a partir do momento em que seus pais the contam histórias, as quais provocam a imaginação literária, inspiram preocupação com 0 destino dos personagens mesmo sem conhecê-los, e instigam a percepção do respeito aos aspectos ocultos 
do mundo interior desses personagens. À medida em que vão dominando sua imaginação, tornamse capazes de sentir compaixão, realçando a empatia em suas ações. Além disso, permitem a compreensão sobre "como uma história que impõe estereótipos às raças pode afetar a autoestima e a conquista, e como 0 amor nos permite fazer julgamentos mais fundamentados sobre questões relacionadas à discriminação e educação positivas" (NUSSBAUM, 2005, p.68).

Para Nussbaum (2015), um dos relatos mais influentes e atraentes da representação criativa é feito pelo pediatra e psicanalista britânico Donald Winnicott (1896-1971), que acreditava que a atividade lúdica é crucial durante toda a fase de desenvolvimento, sendo a "chave para 0 desenvolvimento de uma personalidade saudável" (NUSSBAUM, 2015, p.99). A criança nasce ligada em si mesma, realinhando uma figura narcisista, mas com o jogo, a ludicidade e brincadeiras. Segundo o psicanalista, ela vai aprendendo no decorrer da vida e vai desenvolvendo o olhar pelo outro. Segundo Nussbaum (2015, p. 100), "Winnicott percebeu que o 'espaço potencial' entre as pessoas não se fecha só porque elas se tornam adultas, e que a vida é cheia de maravilhamento e brincadeiras e que na área de relacionamento a brincadeira é crucial". Dessa forma, as pessoas podem se fechar, esquecendo o mundo interior dos outros, ou podem conservar e desenvolver mais a capacidade de adotar as formas dos outros, na imaginação, de vida interior, superando o narcisismo.

$\mathrm{Na}$ interpretação de Nussbaum (2015, p.101), Winnicott enfatizava com frequência que a atividade lúdica tem um papel importante na formação da cidadania democrática, onde o "brincar ensina as pessoas a serem capazes de conviver com os outros sem controlar; e liga as experiências de vulnerabilidade e surpresa à curiosidade e ao maravilhamento, não à ansiedade paralisante". Para o psicanalista, a pergunta sobre como os adultos mantêm a capacidade de brincar após terem deixado para trás o universo das brincadeiras de criança é sustentada no papel fundamental das artes, que se caracteriza na capacidade de preservar e intensificar 0 desenvolvimento do "espaço lúdico". Além disso, ele considerava que o papel das artes na vida humana era, acima de tudo, o de alimentar e ampliar a capacidade de empatia, e é por isso que elas desempenham um papel vital, pois cultivam poderes da imaginação que são essenciais para a construção da cidadania (NUSSBAUM, 2005, p.54).

Nesse contexto argumentativo de Nussbaum (2015), seguindo os passos de Winnicott, é imperioso destacar que a percepção do outro, a empatia, não são questões que surgem no ser humano de forma inata. A empatia surge por meio de conquistas alcançadas pelo desenvolvimento físico e psicológico da criança, com a percepção constante que ela realiza, através do tempo, das diferenças entre 0 eu e 0 outro. $E$ isso já ocorre na mais tenra idade, quando os bebês, através de 
estímulos e sensações visuais e táteis, começam a perceber e identificar aquilo que faz e aquilo que não faz parte de seu corpo. Assim, no caso da pessoa adulta que não conseguiu desenvolver esse olhar pelo outro na infância, é possível que ela construa esse conceito a partir das artes, do limite e das humanidades.

A arte, assim como a literatura, é considerada elemento primordial para o fortalecimento emocional e imaginativo do ser humano, porque possibilita às crianças desenvolver capacidade ou recursos emocionais que estimulam o autoconhecimento ou mesmo o reconhecimento dos outros como iguais, merecedores e possuidores de importantes valores sociais, criando conceitos iniciais de cidadania, além da empatia, do reconhecimento da capacidade de percepção do outro e do exercício da imaginação narrativa.

Com base nisso, Nussbaum (2015) propõe que a imaginação seja levada o para espaço educacional, pois ter uma grandeza que pode formar cidadania, e destaca o papel da família, das escolas de ensino básico e das universidades como entidades fundamentais para 0 desenvolvimento da compreensão das pessoas. Para que isso aconteça da melhor forma, essas instituições têm que reservar um espaço de destaque nos currículos para as humanidades e artes, ampliando a educação participativa que atrai a capacidade de entender o mundo através do olhar de outra pessoa.

A autora enfatiza que o brincar é um tipo de atividade que ocorre no espaço entre as pessoas, denominado de "espaço potencial" e que faz com que as pessoas (em especial, crianças e adultos) criem condições de expressar a noção de alteridade de maneira mais segura do que aquela provocada quando ocorre um encontro direto com outro, fazendo com que os envolvidos se apropriem e desenvolvam uma prática inestimável no exercício da empatia e de reciprocidade.

É nesse contexto que a imaginação narrativa é construída de forma especial - pensando na relação entre as pessoas - e desenvolve a empatia e a capacidade de fazer essa ligação com o outro, conduzindo para humanidades. Essa visão humanitária ajuda na criação de nova sociedade em que se cultiva o espírito de compassividade com o outro, ou seja, um cultivo de sociedade humanitária em que a pessoa se coloca no lugar do outro, entendendo que esse pode ser condicionado a partir do lugar ou do espaço em que a pessoa se encontra. (NUSSBAUM, 2015).

Segundo Nussbaum (2015), em todas as sociedades, sempre há um grupo populacional ignorado. Dessa forma, para que esse olhar seja mudado para um olhar mais humanizado em relação a essas pessoas, as instituições escolares devem selecionar obras artísticas que sejam capazes de fazer a crítica da invisibilidade e possam realizar a promoção desses grupos. Podemos 
trazer o caso da população negra no Brasil para exemplificar e a implementação da Lei 11.645/085, que determinou a obrigatoriedade de ensino da cultura afro-brasileiro, africana e indígena no Ensino Básico. Ou seja, a história do negro sempre esteve no currículo escolar, mas na condição de escravo e submisso, gerando uma situação naturalizada nas pessoas, trazendo a ideia de que escravos é uma condição "inerente" à raça negra, o que também constitui um significado preconceituoso e pejorativo, construído e sustentado durante a história da humanidade e fortalecido pelos processos educativos acríticos.

Por fim, ressalta-se ainda que a autora defende a necessidade do cultivo do olhar interior nos alunos, isso é, olhar por si para melhor se descobrir e compreender a sua personalidade, para que se desperte esse olhar com os demais. Por isso, para ela, é importante uma formação inclusiva bem estruturada, por meio das artes e das humanidades, levando em consideração as ideias dos alunos, seu grau de desenvolvimento, como forma de colocá-los com assuntos ligados a gênero, raça, origem étnica e experiências culturais. (NUSSBAUM, 2015).

Ainda, Nussbaum (2015, p.107) também destaca o pensamento de Ralph Ellison, um crítico literário que, junto de Tagore, tem uma reflexão convergente, pois ambos "dão a entender que as escolas que desprezam as artes desprezam oportunidades importantes de defender a cooperação democrática". Tanto Ellison como Tagore justificam que "para alcançar a compreensão plena do que o cidadão democrático precisa, não basta saber que os estigmas sociais e a desigualdade existem; ele tem de passar pela experiência de participar da posição estigmatizada" (NUSSBAUM, 2015, p.107), uma experiência que pode ser amplamente possibilitada pela presença do teatro e da literatura na escola. $O$ teatro e a literatura se tornam, nesse sentido, aliados importantes para a experiência estética e para a educação das emoções.

Nesse sentido, podemos inferir que a educação acontece a partir de um grupo, no qual estão inseridos o educador, o educando e a sociedade, unidos por meio de um processo dialógico que tem por objetivo transformar os jovens em seres conscientes de sua condição no mundo, a fim de se tornarem sujeitos críticos e autônomos, que saibam fazer escolhas prudentes e sejam

5 A título de conhecimento e exemplificação, a Lei 11.645/08 estabeleceu as diretrizes e bases da educação nacional, para incluir no currículo oficial da rede de ensino a obrigatoriedade da temática "História e Cultura Afro-Brasileira e Indígena". A legislação propôs novas diretrizes curriculares para o estudo da história e cultura afro-brasileira, africana e indígena, de modo que os professores têm de ressaltar essa temática em sala de aula, como elemento constituinte e formador da sociedade brasileira, reconhecendo negros e indígenas como sujeitos históricos. Nesse contexto, são valorizados o pensamento e as ideias de importantes intelectuais negros e índios brasileiros, bem como a cultura (música, culinária, dança) e as religiões de matrizes africanas e indígenas. Sem adentrar na discussão sobre o tema, tendo em vista o caráter desta nota ser apenas informativo, registra-se, a título de conhecimento, que a promulgação da Base Nacional Comum Curricular em 2018 ascendeu novamente a discussão sobre tal pauta, tendo em vista que a BNCC não observou de forma fiel essa orientação legal. 
capazes de construir sua história, questionando o mundo, transformando-o no lugar melhor para se viver. Tal processo se dá por meio de uma aprendizagem mobilizada por uma cultura que seja sensível, tanto no conteúdo curricular quanto no modelo pedagógico, estimulando a capacidade de amar e compreender. Portanto, a literatura e as artes figuram como elementos essenciais, tanto para a formação da imaginação narrativa, que dá origem à capacidade de percepção do outro, quanto para a educação das emoções e para a formação humana mais alargada. Tais aspectos serão abordados na seção a seguir.

\section{A EDUCAÇÃO DAS EMOÇÕES E A FORMAÇÃO HUMANA}

O tema das emoções e do cultivo dos sentimentos tem sido assunto recorrente na sociedade contemporânea: está presente na cultura de massas, no cinema, na literatura de autoajuda, nos treinamentos motivacionais, nas campanhas eleitorais, nos apelos publicitários e até mesmo em certos discursos pedagógicos motivacionais. Não faltam críticas que indicam sua superficialidade, sua forma retórica apelativa para seduzir e desviar a atenção, seu efeito narcótico e enganador que manipula os indivíduos para fins suspeitos e questionáveis. Como bem ressaltam Neitzel e Santos (2015, p.30), "as orientações sobre como lidar com as emoções geralmente são dadas por uma cultura de entretenimento e mercadológica", com uma visível intenção de seduzir os potenciais clientes "para o consumo dos produtos da indústria cultural". Embora historicamente as emoções tenham sido retratadas na literatura, na música, nas pinturas, na religião, na filosofia e mesmo na ciência, seu lugar foi secundarizado na educação humana, na ética e na política.

$\mathrm{Na}$ forma como Nussbaum (2005; 2015) aborda a "imaginação narrativa" e o "cultivo da imaginação", as emoções devem ocupar um lugar de destaque. Mas o que significa educar as emoções? Por que precisamos estar atentos à "educabilidade para o governo das emoções"? Qual sua significação para a teoria das capacidades de Nussbaum? Quem deve cuidar das emoções? Em que perspectiva é possível falar em emoções para não cair na vala comum dos apelos mercadológicos ou da simplificação da literatura da autoajuda? Em que medida as emoções têm implicações para a inteligência humana? Quais são suas implicações para uma vida democrática?

Na interpretação de Nussbaum (2012, p.21), "as emoções dão forma à paisagem de nossa vida mental e social", pois são elas que configuram a "paisagem do nosso pensamento", constituem nossa individualidade, nosso caráter, nossas reações diante dos problemas e decisões cotidianas. As emoções são parte das decisões morais e por isso necessitam ser escrutinadas para não tomarmos decisões equivocadas. Nossa vida é marcada por emoções: algumas são 
profundas, intensas, marcantes; outras efêmeras, superficiais, imperceptíveis. Conforme ressaltam Neitzel e Santos (2015, p.33), "as emoções são elementos que permitem perceber 0 mundo e a realidade em que nos inserimos"; e a partir delas "tomamos decisões, avaliamos, fazemos juízos".

Nussbaum (2015) defende que as emoções estão na base da vida democrática, pois a forma como nos relacionamos com os outros e nos envolvemos com certos compromissos coletivos possuem um fundo emocional de pertencimento. Tal posição é corroborada por Victoria Camps (2012, p.30-32) quando defende que as emoções estão na base da virtude cívica e de outras virtudes que possibilitam uma "ética pública" sem a qual um Estado Democrático não pode persistir. Nesse sentido, as emoções estão ligadas profundamente à vida ética e à vida moral dos sujeitos, pois influenciam no modo como julgamos e valoramos nossas atitudes e escolhas. Além disso, têm influência na capacidade de julgar e valorar as atitudes e opções dos outros. Dizendo de forma direta, as emoções estão na base tanto dos inúmeros preconceitos (racial, sexual, religioso, étnico, político, cultural, linguístico) presentes nos indivíduos e compartilhados por grupos quanto nas virtudes que promovem a vida democrática e o reconhecimento das diferenças.

Se as emoções estão na base de nossos julgamentos e escolhas, então, não é possível falar em educação democrática sem a "governabilidade das emoções", pois a educação é sempre emocional, assim como também é moral ou política. "Se a educação formal não o faz, se a sociedade pelas suas instituições não as promove, alguém ou as circunstâncias o farão" (NEITZEL; SANTOS, 2015, p.34). Uma educação desassistida nesse aspecto, moldada pelas circunstâncias, tem mais probabilidade de produzir a proliferação dos preconceitos, 0 autoengano sobre a própria vulnerabilidade e a desumanização decorrente. É nesse aspecto que Nussbaum (2015) chama a atenção para a importância da educação para as emoções das crianças. É fundamental que elas aprendam a proteger o que é bom e a identificar o que é maléfico, que saibam distinguir uma atitude virtuosa de uma prática destrutiva e que tenham noção do que é desejável porque beneficia a todos e respeita as individualidades e do que é repugnante porque provoca sofrimento e marginalização de quem é diferente. Nas palavras da própria Nussbaum (2015, p.108, grifos da autora), "precisamos, portanto, desenvolver o 'olhar interior' dos alunos. Isso significa uma formação cuidadosamente moldada nas artes e nas humanidades [...] que ponha em contato com questões de gênero, raça, etnia e experiência e cooperação transculturais". Essa formação artística pode se tornar um importante antídoto, bem como um potente ingrediente que produz imunidade para não contaminar nossas crianças com o vírus do preconceito. 
A música, o teatro, a literatura, as artes plásticas, as obras de arte, podem se tornar imprescindíveis aliadas para a formação do cidadão do mundo, quando "costumam ser um modo inestimável para começar a compreender as conquistas e sofrimentos de uma cultura diferente da nossa" (NUSSBAUM, 2015, p.108). Por isso, as artes, na visão da autora, deveriam ocupar um papel duplo nas faculdades e nas escolas, uma vez que "desenvolvem não só a capacidade de brincar e de sentir empatia", mas também "tratam de pontos cegos culturais específicos". 0 primeiro diz respeito à forma espontânea realizada em atividades extracurriculares, fora da escola; o segundo "exige um foco mais preciso em áreas de inquirição social". Ambos podem estar conectados, mas só terão êxito para constituir valores democráticos se existir "uma visão normativa sobre o modo pelo qual os seres humanos devem se relacionar entre si", pautados pelo respeito "a uma ideia de dignidade humana equânime".

Nussbaum (2015, p.108-109) ainda adverte que "se não estiver ligada a uma ideia de dignidade humana equânime, a imaginação empática pode ser caprichosa e desiquilibrada". É possível, por exemplo, que sintamos compaixão seletiva, que nos emocionemos afetivamente por pessoas próximas geograficamente ou por alguém com quem nos identificamos em termos de raça ou de classe. Por outro lado, podemos ser insensíveis ao sofrimento de outras pessoas diferentes de nós, tratando-as como meros objetos. Obras de arte, textos literários e gêneros musicais não são isentos de um perfil preconceituoso ou mesmo de uma postura que reforça "sentimentos de compaixão unilaterais". A própria autora ressalta que "crianças que têm sua imaginação estimulada por meio da leitura de literatura racista ou da coisificação pornográfica da mulher não estão cultivando de uma forma adequada às sociedades democráticas". Da mesma forma, não se pode omitir o fato de "que movimentos antidemocráticos têm sabido utilizar as artes, a música e a retórica de modo a contribuir ainda mais para humilhar e estigmatizar determinados grupos e pessoas". Isso significa que "o elemento imaginativo da educação democrática" necessita de cuidadosa seletividade, vigilância epistemológica e cuidados éticos adicionais para não sucumbir ao uso instrumental e antidemocrático. Não seria desejável ver nossas crianças e jovens reforçando na escola certos preconceitos amplamente compartilhados na sociedade; de outra parte, seria desejável que os espaços escolares fossem espaços públicos para exercitar a emoção de se se colocar no lugar daqueles que sofrem preconceitos, são rotulados pelas suas diferenças e sofrem profundas humilhações pela sua cor da pele, condição social, opção sexual ou credo religioso.

\section{CONSIDERAÇÕES FINAIS}


Talvez seja pouco convincente e parcialmente ineficiente fazer pregações religiosas, discursos políticos inflamados ou regramentos jurídicos rigorosos que possam combater 0 racismo, o machismo ou a humilhação; no entanto, de outra parte, a história nos mostra que a presença decisiva de bons filmes, de qualificada literatura e de boas peças teatrais e o testemunho de homens e mulheres engajados num projeto que combata todos esses preconceitos pode se mostrar promissor para a formação de uma mentalidade democrática que seja capaz de mitigar as formas perversas e excludentes de relacionamento que se manifestam por meio de uma forma estereotipada de como deve ser uma pessoa humana.

Conforme anunciado na introdução, o presente texto teve por objetivo analisar de que forma a educação das emoções e a imaginação narrativa podem se tornar potencialmente produtivas para constituir uma concepção alargada de formação humana. Nossa hipótese de trabalho é de que, a partir de reflexões de Nussbaum (2015), o ensino da literatura e das artes pode estimular a compreensão de diversas formas de vivências e pode desenvolver o "olhar interior" dos alunos, colocando-os em contato com questões de gênero, raça, etnia e cooperação transcultural.

Conforme desenvolvemos no texto, não se trata de incluir de forma artificial ou técnica a literatura, a música ou as artes de modo geral no processo formativo escolar, pois isso poderia resultar num formato "caprichoso e desequilibrado" de "imaginação empática", reforçando sentimentos de compaixão unilaterais. Não é qualquer literatura ou qualquer obra da arte que se tornam mediadoras de um processo educativo que promova a formação de "cidadãos do mundo". Experiências históricas mostram que governos fascistas e ditadores também podem instrumentalizar as artes para seu próprio benefício. Nesse sentido, o trabalho com a literatura, a música e as artes se torna imprescindível para a preservação e o fortalecimento de uma sociedade democrática, desde que haja um bom planejamento e que os professores tenham uma sólida e adequada formação cultural, pedagógica e científica, e, principalmente, desde que haja um projeto democrático de escolarização e formação humana.

\section{REFERÊNCIAS}

BISSOTO, A educação sociocomunitária: reflexões sobre o educar para a autonomia. EccoS Rev. Cient., São Paulo, n. 41, p. 157-172, set./dez. 2016. Disponível em: http://periodicos.uninove.br/eccos/article/view/4566. Acesso em 13 out 2020. 
CAMPOS, Marcelo Mallet Siqueira. A expansão da rede federal de educação profissional, técnica e tecnológica no período 2003-2014: uma análise a partir da abordagem das capacitações. Disponível em: http://coral.ufsm.br/seminarioeconomia/images/anais_2016. Acesso em 13 out 2020.

CAMPS, Victoria. El gobierno de las emociones. Barcelona: Herder Editorial, 2012.

DEWEY, Jonh. A arte como experiência. Trad. Vera Ribeiro. São Paulo: Martins Fontes, 2010.

DEWEY, John. Reconstrução em Filosofia. Trad. António Pinto de Carvalho. São Paulo: Companhia Nacional, 1958.

LAVAL, C. A Escola não é uma empresa: o neo-liberalismo em ataque ao ensino público. Londrina: Editora Planta, 2004.

NEITZEL, Odair; SANTOS, Claudecir dos. A educabilidade das emoções: implicações éticas e políticas. Controvérsia, São Leopoldo, v.11, n.1, p.29-43, jan./abr., 2015. Disponível em: http://revistas.unisinos.br/index.php/controversia/article/viewFile/10346/4832. Acesso em: 20 de nov. 2020.

NUSSBAUM, Martha. Crear Capacidades: propuesta para el desarrollo humano. Barcelona: Paidós, 2012.

NUSSBAUM, Martha. Sem fins lucrativos: por que a democracia precisa das humanidades. Tradução de Fernando Santos. São Paulo: Editora WMF Martins Fontes, 2015.

NUSSBAUM, Martha. Educação e Justiça Social.Trad. de Graça Lami. Ramada: Lisboa: Pedago, 2014.

NUSSBAUM, Martha. El cultivo de la humanidade: uma defensa clásica de la reforma em la educación liberal. Barcelona: Paidós, 2005.

NUSSBAUM, Martha. Fronteiras da Justiça: deficiência, nacionalidade, pertencimento à espécie. Tradução de Susana de Castro. São Paulo: Martins Fontes, 2013.

NUSSBAUM, Martha. Paisajes del pensamiento: la inteligencia de las emociones. Trad. Araceli Maira. Barcelona: Paidós, 2012.

WINNICOTT, Donald. O brincar e a realidade. Rio de Janeiro: Imago, 1975. 